\title{
Teleconnection mechanism between millennial-scale Asian Monsoon dynamics and North Atlantic climate
}

\author{
Kana Nagashima ${ }^{1}$ and Ryuj Tada ${ }^{2}$ \\ 'Research Institute for Global Change, Japan Agency for Marine-Earth Science and Technology, Yokosuka, Japan; nagashimak@jamstec.go.jp \\ ${ }^{2}$ Department of Earth and Planetary Sciences, Graduate School of Science, University of Tokyo, Japan
}

We present evidence for millennial-scale changes of the westerly jet path over East Asia during the last glacial period and suggest that the westerly jet plays a critical role in a millennial-scale climate teleconnection between Asia and the North Atlantic.

$T^{\text {he }}$ he $\delta^{18} \mathrm{O}$ records of stalagmites from the Hulu Cave in southeastern China (Wang et al. 2001) and the grayscale profile of hemipelagic sediments from the Japan Sea (Tada 2004; Tada et al. 1999; core MD01-2407) show millennialscale variations in East Asian Summer Monsoon (EASM) rainfall along the Yangtze River (Fig. 1) in association with Dansgaard-Oeschger (D-O) events (Fig. 2). Moreover, annual-resolution studies of a Greenland ice core suggest that decreases in the eolian dust flux from midlatitude Asian deserts approximately coincided with or even led the temperature rises at the onsets of the BøllingAllerød, the Pre-Boreal, and a prominent D-O interstadial (Steffensen et al. 2008; Thomas et al. 2009). These findings suggest a direct linkage of millennial-scale climate changes between Asia and the North Atlantic. However, the dynamics of such a teleconnection remains unresolved.

Here we focus on the westerly jet because of its high potential to link climate changes between East Asia and the North Atlantic. At present, the westerly jet axis over East Asia passes south of the Himalayas during winter and early spring, and then jumps to north of the Tibetan Plateau in late spring to early summer in association with intensified Hadley Cell circulation (Schiemann et al. 2009). Wang et al. (2011) proposed that for a summer monsoon rainband to develop along the Yangtze River, the westerly jet needs to be at or slightly north of the river's latitude during summer. This mechanism is well explained by Sampe and Xie (2010). They demonstrated that eastward advection of warm air from the eastern flank of the Tibetan Plateau along the westerly jet axis triggers the convection that forms the rainband. They further showed that the westerly jet anchors the rainband by steering transient weather disturbances, which promote convection by intensifying moisture advection with upward motion. Over the North Atlantic, the westerly jet also steers transient eddies that bring precipitation, and its path is largely controlled by the sea-ice extent and meridional gradient of sea surface temperature (Laîné et al. 2009). By analogy with the present close linkage of the westerly jet path with the positions of both the EASM rainband and weather fronts in the North Atlantic, we infer that dynamic changes in the westerly jet path may have played a critical role in linking millennial-scale changes in EASM precipitation and North Atlantic climate during the last glacial (Fang et al. 1999; Tada 2004). Supporting this inference, productivity changes of the western Mediterranean Sea estimated from geochemical proxies of marine sediments (Moreno et al. 2004, 2005) suggest westerly jet path changes over the North Atlantic in association with D-O events. However, millennial-scale changes of the westerly jet path over East Asia have not yet been demonstrated. Here we introduce the result of our recent study that reconstructed variations in the westerly jet path over East Asia during the last glacial by examining the provenance and grain size of Asian

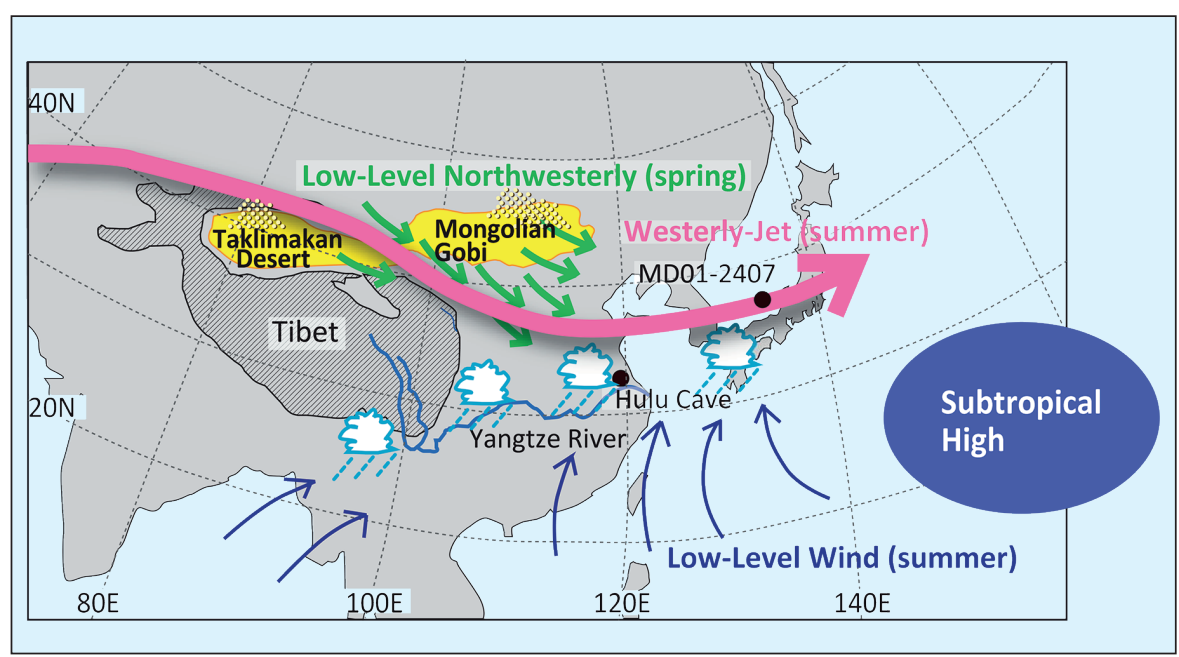

Figure 1: Spring and summer atmospheric circulation patterns and the East Asian Summer Monsoon rainband over East Asia (shown by clouds). The locations of the marine sediment core MD01-2407, the Hulu Cave speleothem, and important geographical features are also shown. dust in a sediment core from the Japan Sea (Nagashima et al. 2011).

\section{Dust provenance reflects seasonal shifts of the westerly jet}

Nagashima et al. (2011) demonstrated that the relative abundance of Asian dust emitted from two major Asian deserts, the Taklimakan Desert and the Gobi Desert in southern Mongolia (hereafter, Mongolian Gobi) reflects changes in the seasonal northward movement of the westerly jet axis. At present, dust emission events in both these deserts are most frequent in spring because the large temperature gradient between high and middle latitudes and the resulting synoptic-scale disturbance in the atmospheric circulation generates strong cold fronts that give rise to storms (Roe 2009). In spring, severe dust storms are approximately twice as frequent in the Mongolian Gobi as in the Taklimakan (Kurosaki and Mikami 2005; Sun et al. 2001) because the Mongolian Gobi lies along the main pathway of cold air masses from Siberia. In this season, the emitted dust is transported eastward 


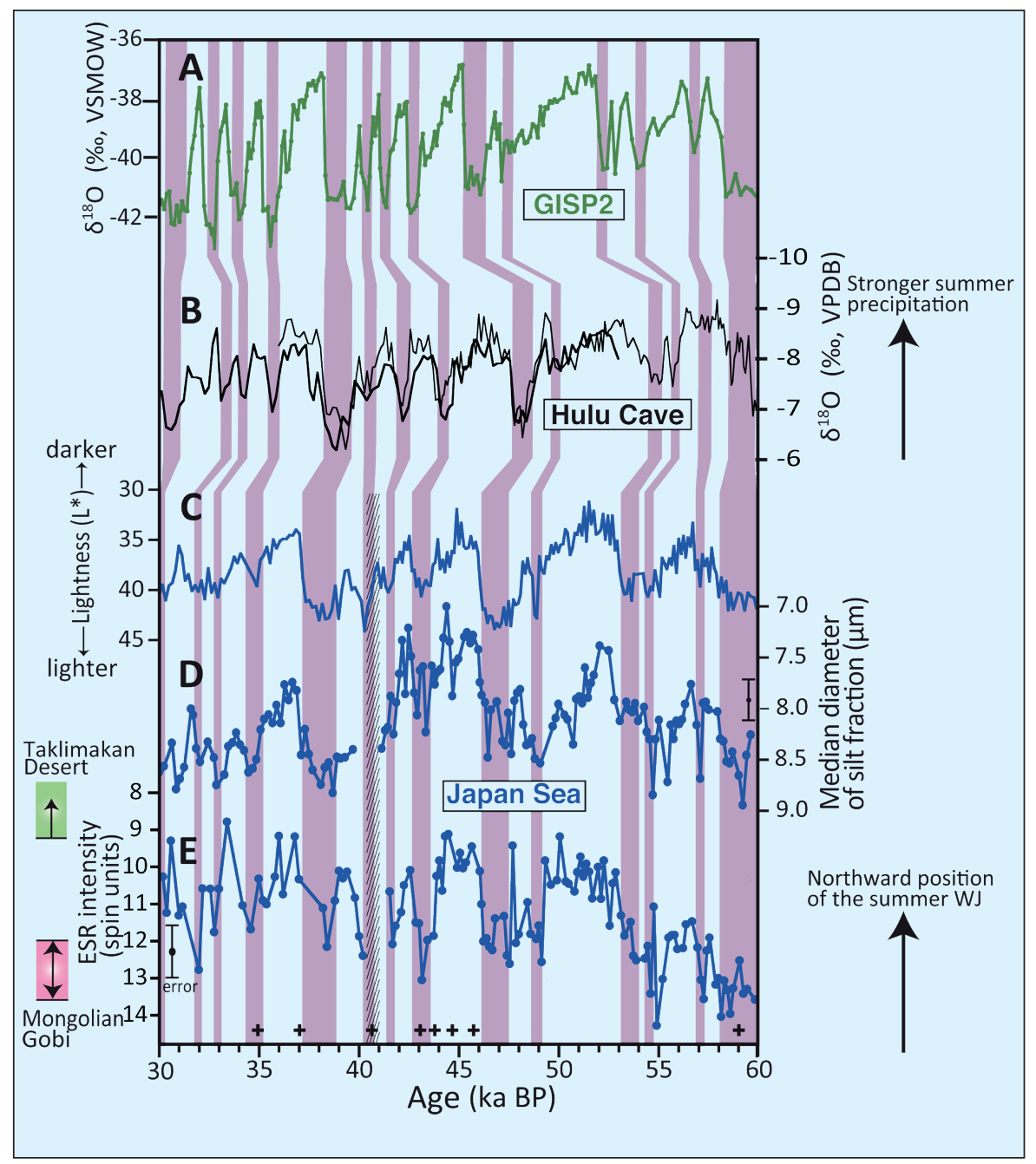

Figure 2: Dust provenance records from the Japan Sea compared with paleoclimate records from Greenland and southeastern China. A) GISP2 $\delta^{18} \mathrm{O}$ record (Grootes and Stuiver 1997); (B) Hulu Cave stalagmite $\delta^{18} \mathrm{O}$ record (Wang et al. 2001); (C) lightness ( $L^{*}$; Watanabe et al. 2007), (D) median grain size of the silt fraction, and (E) ESR intensity of silt-sized quartz (Nagashima et al. 2011) in core MD01-2407 from the Japan Sea. Plus signs (+) mark age-control points in core MD01-2407 (Yokoyama et al. 2007). Vertical purple bars indicate stadials in GISP2, heavier oxygen isotope (weak Asian monsoon) events in Hulu Cave, and light-colored layers in core MD01-2407. The vertical hatched bar indicates an interval in the core containing volcanic ash.

mostly by near-surface northwesterly winds. During summer, however, the latitudinal temperature gradient is smaller, suppressing storm event frequency in the Gobi (Roe 2009), whereas dust emission event frequency remains high in the Taklimakan (Kurosaki and Mikami 2005) because of the local circulation system between the desert and high surrounding mountains (Abe et al. 2005). When winds blowing against the northern margin of the Tibetan Plateau lift the dust above $5000 \mathrm{~m}$, the emitted dust can be entrained into the westerly jet, which is north of the plateau during summer, and transported long distances. Thus, the relative abundance of dust from the Taklimakan versus the Mongolian Gobi mainly reflects the relative frequency of summer versus spring-type dust events. Since spring-type dust events cease once the westerly jet jumps to the north of the Tibetan Plateau (Nagashima et al. 2011), changes in the relative abundance for Mongolian Gobi (Nagashima et al. 2011). Lower ESR signal intensities (larger contribution from the Taklimakan Desert) clearly correspond to dark layers (D-O interstadials) and higher intensities (larger contribution from the Mongolian Gobi) to light layers (D-O stadials) (Fig. 2C, E). These inferred differences in dust provenance between dark and light layers are supported by the smaller median diameter of the silt fraction within the dark layers (Fig. 2D). Eolian grain size decreases with increasing distance from the source, and the Taklimakan Desert is more distant from the Japan Sea than the Mongolian Gobi; thus, the median grain size of eolian dust from the Taklimakan is smaller than that from the Mongolian Gobi. The dominance of dust from the Taklimakan in D-O interstadials suggests that the westerly jet jumped to the north of the Tibetan Plateau earlier during interstadials, favoring the development of a rainband along the Yangtze River during summer (Sampe and Xie 2010). Therefore, a northerly migration of the westerly jet path over East Asia can explain the increased precipitation over the Yangtze River during D-O interstadials (Fig. 2B), and also links millennial-scale changes in the EASM with those in the North Atlantic climate.

Oxygen isotope records of speleothems from the southwestern United States also suggest a northward shift of the polar jet during D-O interstadials (Asmerom et al. 2010). Furthermore, speleothem growth patterns in northeastern Brazil (Wang et al. 2004) and the chemical composition of Lake Malawi (East Africa) sediments (Brown et al. 2007) reveal a northward shift of the Intertropical Convergence Zone (ITCZ) during $\mathrm{D}-\mathrm{O}$ interstadials over these respective regions. Taken together, these results suggest that a dynamic N-S displacement of the atmospheric circulation pattern (the westerly jet at midlatitudes and the ITCZ at low latitudes) may almost simultaneously propagate D-O events on hemispheric and interhemispheric scales.

\section{Millennial-scale teleconnection via the westerly jet}

Hemipelagic sediments in the Japan Sea are characterized by alternating dark and light layers; light layers were deposited during D-O stadials and dark layers during D-O interstadials (Tada 2004; Tada et al. 1999; Fig. 2C). The ESR signal intensities of silt-sized (eolian) quartz (Nagashima et al. 2007) in samples from core MD01-2407 ranged between values of 6.6-9.2 for Taklimakan and 12.0-13.6

\section{Selected references}

Full reference list online under:

http://www.pages-igbp.org/products/newsletters/ref2012_2.pdf

Nagashima Ket al. (2011) Journal of Asian Earth Sciences 40: 1214-1220 Sampe T and Xie S-P (2010) Journal of Climate 23: 113-134 Sun Y et al. (2007) Atmospheric Environment 41: 8537-8548 Wang C, Liang X-Z, Samel AN (2011) Journal of Climate 24: 2116-2133 Wang YJ et al. (2001) Science 294: 2345-2348 